\title{
The Influence of Different Thinking Pattern between English and Chinese News Comment
}

\author{
A Case Study
}

\author{
Lili Sun \\ College English teaching department \\ Zao Zhuang College \\ Zao Zhuang, China \\ libbysun@163.com
}

\begin{abstract}
With the globalization, people communicate with each other more frequently and extensively. Whatever the oral or written form, the culture, especially the thinking pattern has a great effect on the communication. Language reflects our thinking and thinking can be expressed on different language form. Based on the previous study on different thinking patterns.
\end{abstract} linear

Keywords—thinking pattern; synthetic; analytic; cyclical;

\section{LITERATURE REVIEW}

When the key words "western and eastern thinking patterns" are searched from the year 2005-2014 in the journal corpus, 2,634 papers are found. Those papers are analyzed from different perspectives, such as linguistics features, writing styles, discourse analysis, cultural analysis, translation angles, etc. Li Songtao (2005), Liu Hong (2005), Yu Xiaoji (2011), Luo Mingli (2011), Li Meiying (2007) studied the English and Chinese writing by Chinese ESL learners from contrastive cultural analysis. Wei Zaijing (2006), Li Bing(2011), Lv Cancan (2007) studied cultural differences and translation. Genre analysis can be used to large amount of texts with significant similarities and differences especially in rhetorical purpose, form and audience (Dudley-Evans, 1989) and pays more attention to the language features related to particular genre, rhetorical features and style. Kang Qin (2012), Zhao Juan (2013), Li Ping(2011), Li Ping(2005), studied medical abstracts by Chinese and English native speakers. Zhou Wenxuan (2011), Shang Zhihui (2009) made genre analysis of the business letters. Shu Huiqin (2009),Wang Shengyun (2001), Zhang Wei(2003), Xie Hui (2008) studied the different writing styles of Chinese and western news reports from cultural perspective. Dou Weilin (2006) studied the language differences between Chinese and English news reports from cultural perspectives. Since now, a number of studied related to news articles have been undertaken. But most of them are related to the writing styles and few studies are conducted from the language differences. Based on the previous studies, this thesis tries to analyze the different language expression between Chinese and English news articles due to the different thinking patterns.
With the globalization, people all over the world communicate with each other more frequently. There are still more differences in their language expression in oral or written forms. These differences can be attributed to their thinking pattern. Different nations possess different thinking pattern. And the thinking pattern deeply affects one's writing expression. Ji Xianlin (1998:48) points out that the basic difference between Chinese and Western culture lies in the thought pattern. According to Jia Yuxin (1997), generally speaking, Chinese people follow a synthesis, concrete, grouporiented and subjective way. On the contrary, westerners follow an analytic, abstract, objective and ego-centric way.

\section{SIGNIFICANCE OF THE STUDY}

News articles especially online news are very important for current social communication. Although globalization provides an unprecedented opportunity to contacts, it is still very hard for people to express themselves and communicate with others properly and effectively. This study tries to seek out how the different thinking patterns are reflected in English and Chinese news comments. With the case study, the different thinking pattern between westerners and Chinese people can be explained clearly and concretely. We can analyze it from the following aspects: synthetic thought vs. analytic Thought, cyclical thought vs. linear thought.

\section{A. For Synthetic Thought VS. Analytic Thought}

The differences lead us to use more compound sentences in Chinese and more subordinate sentences in English. In writing, it can be shown that in Chinese, the writers tend to use long articles and more words to express their opinions extensively. Unlike English writers, they express their own points very clearly and intensively. In order to express themselves clearly, conjunctions and figures are frequently used in English articles. Fewer conjunctions and figures are used in Chinese articles.

\section{B. For Cyclical Thought vs. Linear Thought}

Chinese people tend to express themselves not so directly. They often express their view indirectly, softly and 
discursively. So adjectives and metaphors are more frequently used to express more vividly. Chinese writers extensively employ more examples and direct quotes to express their viewpoint, while English writers tend to use less direct citation and examples. They explain their views in a more detailed way.

\section{Research Questions}

As is mentioned above, the purpose of the study was to investigate the differences between Chinese and English comments in terms of different thinking patterns. The major hypothesis of the study is as following:

Hypothesis 1: There are more adjectives and less nouns used in Chinese comments than in English comments.

Hypothesis 2: There are more quotations and examples in Chinese comments than in English comments.

Hypothesis 3: Fewer figures and conjunctions are employed in Chinese comments than in English comments.

Hypothesis 4: Chinese articles are longer than English articles.

\section{Data Collection and Procedure}

The corpus for this study comprises 40 pieces of news commentary-20 Chinese and 20 English. The Chinese ones are collected from Xinhua news agency website (Xinhua). The English ones are collected from the Associated Press websites (AP). These 40 pieces of news are related to the same topics. The reason why we choose these two websites is that Xinhua news websites and the Associated Press are the most important news sources for Chinese and American. So the language used is standard and typical.

For the forty pieces of news comments, 10 articles were chosen randomly for each language to form the corpus of present study. And each 10 articles are related to the same event and are fixed in the similar time. During the analysis, qualitative and quantitative researches are combined.

\section{FINDINGS AND DISCUSSIONS}

\section{A. Synthetic Thought VS. Analytic Thought}

As is discussed above, for this group of thought differences, it can be shown that in Chinese, the writers tend to use long articles and more words to express their opinions extensively. Unlike English writers, they express their own points very clearly and intensively. In order to express themselves clearly, conjunctions and figures are frequently used in English articles. Fewer conjunctions and figures are used in Chinese articles.

The length of the news leads and titles are counted. There are obvious gap between Chinese news articles and English news articles. For English headlines, the total words of the headlines range from 7-10 words. The English leads are also very brief and the average words for total leads are 25 words. In Chinese news articles, there are far more words in news headlines and leads. For the headlines, the average words are 19.8. For the leads, the average words are 133.8. The figures can be shown as following:

TABLE I. MEAN NUMBER OF WORDS FOR NEWS HEADLINES AND LEADS

\begin{tabular}{|c|c|c|c|}
\hline category & sources & mean & Number(article) \\
\hline \multirow{2}{*}{$\begin{array}{c}\text { Words } \\
\text { of headlines }\end{array}$} & AP & 19.8 & 10 \\
\cline { 2 - 4 } & Xinhua & 8.6 & 10 \\
\hline \multirow{2}{*}{$\begin{array}{c}\text { Words } \\
\text { of leads }\end{array}$} & AP & 25 & 10 \\
\cline { 2 - 4 } & Xinhua & 133.8 & 10 \\
\hline
\end{tabular}

From the above table, the difference between the two kinds of news articles is obvious. With the assistance of the software SPSS, it shows that the sig. $0.001(<0.05)$, so there is obvious difference between the two kinds of news articles in terms of news leads and headlines. Here are some examples:

Example 1. 张田勘: 船长逃命和教师自杀, 国民性的两 面? English translation: Zhang Tianzhen: the captain's escaping and teacher's suiciding is it the two sides of the national character? (Xinhua, 2014-04-21 08:18:29)

Was Park Right to Condemn FerryCrew (AP, Apr 21, 2014)

Example 2. 弃船逃生的船长 比“范跑跑”恶劣百倍 (Xinhua, 2014-04-21 09:56:36)

English translation: Abandon ship The captain who abandoned the ship and escaped for life was one hundred times worse than the "runaway fan"

After Sewol Tragedy, Government Says No to School Trips (AP, Apr 21, 2014)

Example 3. 如何看待韩国获救副校长引处自杀(Xinhua, 2014-04-21 10:02:33)

English translation: How to see Korea rescued vice President to commit suicide?

Time to rethink 'hurry, hurry' culture of Korea (AP, APR 22, 2014 7:45 AM)

Example 4. 韩国轮船沉没: 责任和担当比生命更重要 (Xinhua,2014-04-21 10:05:57)

English translation: The ship sank in South Korearesponsibility and duty is more important than life

South Korea Divers Carry Out Ferry Mission in NearTotal Darkness (AP, April 21, 2014, 9:39 p.m.)

From the four groups of headlines, it is obvious that the English headlines are much shorter than the Chinese ones. This kind of feature is attributed to the thinking pattern of Chinese people and westerners. It is proved that Chinese people belong to the synthetic thought and westerners belong to the analytic thought. In the same way, the leads of news articles are also chosen from the corpus. The English and 
Chinese leads are compared. Here are two examples shown as following:

Example 5 South Korea's government isn't taking any chances after last week's Sewol ferry disaster — on Monday, the Education Ministry banned all school trips until at least June. 26 (AP, Apr 21, 2014)

Example 6 韩国海警称, 一艘载有约 450 人的客船在韩 国西南部海域下沉。韩“安全本部”表示, 截至当地时间上 午 11 时, 客轮已完全沉没, 现在已发现第 10 个遇难者, 失踪者中有两名中国人。沉船的原因初步推测一是可能船 内汽车固定装置出问题, 此类滚装船多次因汽车固定装置 出事; 二是韩沉没客轮突然改变航道。(Xinhua, 2014-0421 10:05:57)

English translation: South Korean coast guard said that a passenger ship carrying about 450 people in southwest Korean sea sank. Korea "security department", said by 11 a.m. local time, the liner has been completely sink. A 10th victim has now found and there are two Chinese is missing. Preliminary speculation over the cause of the wreck is that car fixing device in the ship is out of the question. This kind of problem repeatedly happens because of car accident fixtures. The second reason is Korea sank liner suddenly change course.

From the above shown news leads, it is clear that the total number of words in Chinese leads and English leads are widely different.

The analytic thought and the synthetic thought can be reflected on the number of the conjunctions and figure. It is collected as the following table:

TABLE II. MEAN NUMBER OF CONJUNCTIONS AND FIGURES IN WHOLE ARTICLES

\begin{tabular}{|l|l|l|l|}
\hline category & sources & mean & Number(article) \\
\hline \multirow{2}{*}{ conjunctions } & AP & 4.03 & 10 \\
\cline { 2 - 4 } & Xinhua & 1.98 & 10 \\
\hline \multirow{2}{*}{ figures } & AP & 6.25 & 10 \\
\cline { 2 - 4 } & Xinhua & 7.35 & 10 \\
\hline
\end{tabular}

English writers pay more attention to the logic. It is reflected on the use of conjunctions to express the meaning clearly and coherently. Figures are also frequently used to expressly precisely. Chinese sentences are not so closely related and the readers can get its real meaning from the inner and potential structure. Chinese writers pay more attention to the semantic meaning and less to the syntactic structure. So conjunctions are seldom used. According to the study of the news samples, it is found that in Associated Press, each article contains 4 conjunctions on average but in Xinhua news, fewer are found.

\section{B. Cyclical Thought VS. Linear Thought}

It is claimed that Chinese people possess the cyclical thought and English people tend to linear thought . Based on the previous studies, it is proved that Chinese writers tend to write circularly, indirectly and discursively. On the contrary, English people usually write in a linear order and they express their own point of view directly, clearly. According to Matelene(1985), Chinese people have accustomed to using Chengyu, proverbs and piece of folklore. And the Chinese literacy often quotes from maxims, proverbs and analogies. But for western style, they don't write with the "citing references". They express themselves with more detailed information directly and clearly rather than citing from others. In this study, it is assumed that there are more quotations and metaphors in Chinese comments than those in English. From the qualitative study of the news articles, figures can be shown in the following table. More adjectives and fewer nouns appear in Chinese articles than those in English ones.

\section{TABLE III. TABLE 3 THE MEAN NUMBER OF ADJECTIVES AND NOUNS}

\begin{tabular}{|l|l|l|l|}
\hline category & sources & mean & Number(article) \\
\hline adjectives & AP & 15.530 & 10 \\
\cline { 2 - 4 } & Xinhua & 24.140 & 10 \\
\hline \multirow{2}{*}{ nouns } & AP & 119.600 & 10 \\
\cline { 2 - 4 } & Xinhua & 68.183 & 10 \\
\hline
\end{tabular}

As is shown in table 2, in the 10 samples, each article in AP contains about 16 adjectives and in Xinhua agency, the average number of adjectives is about 24 . When the data of the adjectives is analyzed with the software SPSS, the sig. is $0.026(<0.05)$. In the same way, for the number of nouns, the sig. is $0.005(<0.05)$. So the hypothesis is proved to be true. For Chinese people, we tend to express our value, feeling and opinion with adjectives and in English articles; writers tend to use more nouns and verbs instead of adjectives.

The contrastive cyclical thought and linear thought can also be reflected on the use of citation, metaphor, Chengyu and proverbs. With the analysis of the samples, the number of quotation, metaphor and proverbs can be collected. The following is the examples taken from the AP.

Example 9 Park said the captain did not follow a marine traffic controller's instructions to "make the passengers escape," but instead "told the passengers to stay put while they themselves became the first to escape." (AP, Apr 21, 2014)

Example 10 "Legally and ethically, this is an unimaginable act," she said.

"What the captain and part of the crew did is unfathomable from the viewpoint of common sense, unforgivable, murderous behavior," President Park Geun-hye told a Cabinet meeting. (AP, Apr 21, 2014)

Example 11"Close your eyes," Mr. Choi said, after his dive late Monday. "That's what I saw." (AP, Apr 21, 2014) 
Example 12"If you look at the recovered bodies, nearly all of them were found to be wearing life jackets, which shows that nearly all the passengers had recognized that the ship was sinking," Mr. Koh said. (AP, Apr 21, 2014)

The above quotation is taken from the English articles. We can infer that most of the quotations are the direct speeches and no proverbs, no Chengyu appear in the English articles. The quotations appear in the forms "Park said, ... she said, ... Mr. Choi said, ...". However, in Chinese articles, quotations vary in different forms.

Example 13 求生是人之本性, 但后赋的教化, 会导致 人会裹上某种文化习性。在中国古语表述中，也即所谓 “习相远”。(English meaning:Survival is of a human. But after enlightenment, it will lead people to be wrapped in some kind of cultural habits. In China it is an old expression, also known as "their habits that separate them")

Example 14 从职业来说，韩国教师的职业伦理要求一 直很高，对文化习性的获得也很强调“一日三省吾身”，所 以会在教师群体中普遍体现先人后己的行为方式。 (English meaning:In South Korea, requirements of teacher's professional ethics have been high. It was also emphasized to cultural habits of being "a day of three provinces in my body," so "put others before oneself behavior" is generally reflected in the teachers' group)

Example 15 弃船逃生的船长 比“范跑跑”恶劣百 倍.(English meaning: The captain who abandon the ship is one hundred time worse than "runaway fan")

Example 16 船长亦承认弃船先逃, 并哭泣道慊: “对不 起乘客, 对不起他们的家人。”(English meaning: Captain admitted to abandon ship to escape, and cry an apology: "I'm sorry, I'm sorry their families.")

In Chinese articles, quotations are used in different forms. The writers employ direct speech, famous ancient sayings, proverbs and some analogies. Their viewpoint is expressed in various forms. In the examples13,14, “习相远 (their habits that separate them)" is taken from the ancient book "The Three-Character Classic”, “一日三省吾身 (a day of three provinces in my body)"is taken from "the analects of Confucius". The two quotations express that the Confucius thought deeply influences our mind. In example15, analogy is used in the quotation. Here the meaning is not expressed so directly. The name "Fan Paopao" is quoted to express the analogy. As Chinese people, we are very clear that "Fan Paopao" refers to a teacher who ran away when the Wenchuan earthquake happened leaving all his students behind. In example 16, it is similar to the English expressions quoted words from speakers directly.

\section{CONCLUSION AND LIMITATION}

In this study, we analyze the different thinking pattern of Chinese and westerners. We talk about the differences from two aspects. One is Cyclical thought vs. linear thought. The other is Synthetic thought vs. analytic Thought. In each group, we analyze the language features influenced by the different thinking patterns. All the hypotheses are proved to be true.

For Chinese news articles, compared with English articles, there are far more words of news headlines and leads. It is clear that the total number of words in Chinese and English articles is widely different. The analytic thought and the synthetic thought can also be reflected on the number of the conjunctions and figure. More adjectives and fewer nouns appear in Chinese articles than in English articles. The contrastive cyclical thought and linear thought can also be reflected on the use of citation, metaphor, Chengyu and proverbs. With the analysis of the samples, it is proved to be true. There are more proverbs and famous ancient words in Chinese articles than in English articles.

Since the sample is limited and the corpus is relatively not large enough. There must be some errors. For our further study, we can set up a much larger corpus. So in this way, the data and the analysis can be more representative and convincing.

\section{REFERENCES}

[1] Dudley-Evans, Tony. An outline of the value of genre analysis in LSP work. Oxford: Modern English Publications, 1989.

[2] Huiqin Shu. Contrastive study on disaster news from China daily and New York Times, Shanghai Foreign Language University, 2009:12.

[3] Matalene, Carolyrn. Contrastive rhetoric: an American writing teacher in China. College English, 1985(47): 789-808.

[4] Meiying Li. English and Chinese Thought Pattern on Students' English Writing Senior from Middle School, Journal of English Basic Education, 2007(9.)

[5] Qin Kang \& Sun Ping. Genre analysis on the English abstracts from scientific research papers, Foreign Language Teaching, 2012(05):28-31.

[6] Weilin Dou. Impacts of Chinese and Western thought patterns on writing style of business news-A comparative analysis of samples from China Daily and Financial Time, Foreign language teaching and research, vol(4),2006.

[7] Wenxuan Zhou. Genre analysis on business English, Foreign Language Learning Journal, 2011(06):48-50.

[8] Xianlin Ji. Some advice on the construction of the humanity in $21 \mathrm{st}$ century, Journal of Literature, history, philosophy, 1998(01):48.

[9] Zaijing Wei. The Switch from Static to Dynamic Translation: the Perspective from the Way of Thought Patterns Between East and West, Shandong Foreign Language Teaching Journal, 2006(06). 